\title{
Os Paradoxos da presença da Igreja católica nas redes
}

\author{
The paradoxes of the presence of the Catholic Church in the networks
}

\author{
Carlos Eduardo Souza Aguiar*
}

\begin{abstract}
Resumo
Esta Comunicação busca compreender três diferentes paradoxos provocados pela intensa presença institucional da Igreja Católica nas redes digitais. Inicialmente, nós analisamos o contraste existente entre a tradicional estrutura analógica e hierárquica da Igreja e a estrutura horizontal e colaborativa que emerge na sociedade contemporânea graças ao advento das redes digitais. Em seguida, nós colocamos em evidência a incompatibilidade entre dois modelos comunicativos distintos, o modelo da disseminação das boas novas que caracteriza a tradição comunicativa católica e o modelo dialógico suscitado pela natureza comunicacional das redes digitais. Finalmente, nós analisamos o paradoxo existente entre a prática comunicativa da igreja, caracterizada por uma abordagem instrumental dos meios e parcialmente baseado na teologia agostiniana, e um novo discurso eclesiástico emergente que, ao buscar adaptar-se à nova realidade comunicacional, prega que o principal desafio da instituição não é saber como bem utilizar e empregar as novas tecnologias, mas colaborar na compreensão profunda desse novo ambiente.
\end{abstract}

Palavras-chave: sacralidade digital; teologia da comunicação; redes; religião digital; Igreja católica.

\begin{abstract}
The purpose of this paper is to understand three different paradoxes caused by a strong institutional presence of the Catholic Church in the digital networks. Initially, we analyse the existing contrast between the analogue and hierarchical structure of the church and the horizontal and collaborative structure of the networks. Then, we put in evidence the incompatibility between two different models of communication, the model of the dissemination of the good news that characterizes the tradition of Catholic communication and the dialogic model raised by the communicational nature of digital networks. Finally, we analyse the paradox that exists between the communicative practice of the church, characterized by an instrumental approach of the media and partly based on Augustinian theology and a new emerging ecclesiastical discourse that seeks to adapt to the new communicational reality preaching that the main challenge of the institution is not know how to use and employ properly the new technologies, but collaborate in the deep understanding of this new environment.
\end{abstract}

Key Words: digital sacredness, theology of communication; networks; digital religion; Catholic church.

Comunicação submetida em 17 de outubro de 2016 e aprovada em 29 de junho de 2017.

* Doutor em Sociologia (Université Sorbonne Paris Cité), mestre em Ciências da Comunicação (USP), especialista em Ciências da Religião (PUC-SP) e graduado em Filosofia (FFLCH-USP) e em Comunicação Social (ECA-USP). É professor de Filosofia da Faculdade Paulus de Tecnologia e Comunicação - FAPCOM. País de Origem: Brasil. E-mail: cadu.s.aguiar@gmail.com

Horizonte, Belo Horizonte, v. 15, n. 46, p. 638-657, abr./jun. 2017 - ISSN 2175-5841 


\section{Introdução}

O deslocamento do catolicismo para as redes digitais já não espanta nem os espíritos mais conservadores. Sites institucionais, ritos online, redes sociais de fiéis, aplicativos para celulares e tabletes. Eis as inegáveis evidências de que a religião se posiciona cada vez mais intensamente no ambiente digital, provocando um tipo de experiência que vai muito além da simples disponibilização de conteúdos por novos instrumentos. O catolicismo, antes, relaciona-se simbioticamente com essas tecnologias que - não sendo simplesmente ferramentas comunicativas - colaboram na emergência de uma nova ambiência espiritual na qual, inclusive, surgem diferentes formas de vivenciar a religião, materializadas em velários ou capelas virtuais, por exemplo.

Desse modo, não é por acaso que os chamados meios de comunicação estão no centro do debate católico, entendidos como um domínio estratégico para o futuro da instituição. Pelo menos desde as diretivas do Concílio Vaticano II, momento no qual a própria noção de "comunicação social" - termo empregado no decreto conciliar inter mirifica de 1963 - surge como a tradução católica de mass media (DOUYÈRE, 2001). Em consequência das transformações tecnológicas ocorridas nas últimas décadas, a Igreja buscou adaptar-se a cada nova arquitetura comunicativa surgida no mercado. Uma das últimas novidades, nesse sentido, foi a recente criação da conta Instagram do Papa Francisco batizada @Franciscus.

Todo esse esforço comunicativo, evidentemente, suscitou uma longa reflexão teórica consolidada em inúmeros documentos oficiais e obras teológicas consagradas à relação entre meios digitais e Igreja. Analisados em seu conjunto, fica evidente que existe um encorajamento à adesão do corpo da Igreja ao novo ambiente comunicativo. Para a Igreja, as redes não somente permitiriam a realização de inúmeros preceitos cristãos, mas elas exigem da própria instituição a responsabilidade em colaborar na compreensão conceitual profunda do contexto tecnológico e social contemporâneo (SPADARO, 2012). 
Entretanto, esse alvoroço em relação ao ambiente digital é acompanhado, curiosamente, por inúmeras contradições. A mais evidente entre elas é o imperativo da presença física como condição necessária aos sacramentos. Trata-se de uma resistência constante na história da relação entre meios de comunicação e Igreja, vide a não validade de uma missa televisionada, cujo valor é somente espiritual, ou ainda de uma confissão por telefone. Em suma, a validade e autenticidade dos sacramentos exige a presença, em carne e osso, do fiel.

No entanto, existem contradições e paradoxos mais sutis e que são explorados neste artigo a partir da análise de textos e documentos eclesiásticos chaves que portam sobre a relação internet e Igreja à luz de uma abordagem epistemológica da comunicação na qual os meios são observados como fatores ativos do social, isto é, não somente como instrumentos neutros de transmissão de mensagens mas, sobretudo, como ambientes (MEYROWITZ, 1985). Dessa maneira, as formas contemporâneas de comunicação em rede engendram um novo ambiente que as instituições, inclusive religiosas, buscam ocupar. Fruto desse descolamento institucional, aparecem choques e paradoxos que marcam os limites da comunicação digital da Igreja.

$\mathrm{Na}$ presente comunicação, destacaremos três desses paradoxos ${ }^{1}$. Primeiramente, analisamos o antagonismo entre a verticalidade na qual se baseia a Igreja e a contemporaneidade, marcada pela crise desses processos verticais graças às redes horizontais e de colaboração. Em seguida, destaca-se o conflito entre a natureza dialógica das redes em oposição à ideia cristã da boa comunicação, que é a disseminação. Finalmente, o último paradoxo está relacionado com a posição teológica, consagrada por Agostinho, que entende que a matéria, isto é, os meios, não tem o poder de transformar a verdade e, portanto, é preciso somente utilizá-los e não apreciá-los por si só, uma abordagem que faz parte da tradição católica e que

\footnotetext{
${ }^{1}$ Além das particularidades das diversas instituições religiosas que exigem diferentes abordagens, o próprio campo comunicacional, fortemente impactado pelo advento das tecnologias e redes digitais, permite diferentes aprofundamentos, refletidos em uma extensa bibliografia. Nosso objetivo com essa comunicação é destacar apenas três paradoxos que a presença da religião católica nas redes produz, colaborando com esse rico debate nacional e internacional.
} 
encontra-se institucionalmente na prática cotidiana da comunicação digital, o que está em clara contradição com a ideia defendida pela própria Igreja, ou seja, que seu principal desafio não é saber como bem utilizar essas tecnologias, mas saber como melhor entrar em sintonia com essa nova realidade.

\section{A igreja e a crise das hierarquias}

O primeiro paradoxo que buscamos compreender é de ordem estrutural. Existe um claro contraste entre a estrutura analógica e hierárquica da Igreja e a estrutura horizontal das redes digitais. Neste novo ambiente, os membros do clero possuem potencialmente o mesmo poder comunicativo que qualquer outro ponto da rede. No entanto, o que constitui hoje o catolicismo digital é apenas parcialmente determinado pelas iniciativas oficiais, o que, evidentemente, enfraquece o poder da Igreja enquanto instituição.

Para refletir sobre esse choque é importante considerar o processo iniciado com o advento dos meios eletrônicos e que o teórico dos meios convertido ao catolicismo Marshall McLuhan denominou como "processo de desromanização" (MCLUHAN, 2010). Esse processo, evidentemente, afeta diretamente a instituição, pois a Igreja fora forjada justamente nos paradigmas romanos, o que explica a relativa crise da Igreja enquanto estrutura hierárquica de poder.

Para compreender esse processo, ainda mais radical com o advento do digital, é interessante seguir o argumento de Mcluhan, para quem as diferentes formas dos meios na história da comunicação determinam mudanças na Igreja, em particular no decorrer da renascença com a Revolução de Gutemberg. A tipografia fragilizou a Igreja transformando o fiel em leitor e, por conseguinte, quebrando o monopólio de intepretação de que gozava o clero. $\mathrm{Na}$ idade dos manuscritos, os textos eram raros e caros e somente a elite religiosa tinha acesso a eles. A interpretação oficial era disseminada à base da pirâmide pela oralidade. No entanto, a partir de Gutenberg, todos puderam ler na sua língua materna, e não 
somente escutar as escrituras. Assim, cada um pode também construir seu ponto de vista, o que, evidentemente, foi o fator primordial da posterior reforma protestante.

Além desse cisma, a própria Igreja transformou-se graças à tipografia. Por exemplo, a hierarquia tornou-se mais rígida, precisamente devido a uniformidade que a tipografia permitiu. É justamente a aceleração da imprensa a causa principal do desenvolvimento do centralismo burocrático da Igreja (MCLUHAN, 2010, p. 71). A dita galáxia de Gutemberg reforça, assim, os traços característicos da instituição, fundada sob a tecnologia do alfabeto e da escritura. Apesar do cristianismo ser baseado num livro que registra uma revelação, em tempos primórdios ele era essencialmente uma religião oral. Foi somente depois da institucionalização, a partir dos paradigmas romanos, que o catolicismo tornou-se dogmatizado. Paulo é o personagem chave desse processo ao impor sua formação greco-romana e seu desejo de universalizar o cristianismo.

A esse respeito, o teórico Walter Ong adverte-nos que a palavra revelada por Deus, tal qual definida pela tradição Hebraico-cristã, chegou aos homens em um ponto estratégico da história, quando o mundo oral começou a ser remodelado pela força da escrita alfabética. Para o cristão, isso significa que Deus aparece na história da humanidade no momento oportuno para dar continuidade e estabilidade à "revelação". Naquela época, a tradição oral era ainda dominante, mas, ao mesmo tempo, o alfabeto poderia dar à revelação divina um novo tipo de força que não existiria em um ambiente caracterizado pela oralidade (ONG, 2000). McLuhan acrescenta ainda que a Igreja é extremamente grata a dois conceitos surgidos com a escritura e que intensificaram-se com a imprensa: a hierarquia institucional e a ideia de identidade privada (MCLUHAN, 2010, p. 80).

Todavia, a partir do surgimento da eletricidade e suas tecnologias, todo esse paradigma começou a se saturar. Uma das possíveis interpretações dessa saturação é uma espécie de retorno a uma condição primordial, similar àquela da oralidade. 
O que McLuhan chamou de aldeia global e Walter Ong de oralidade secundária são metáforas interessantes, pois visam fornecer pistas de reflexão acerca desta nova atmosfera contemporânea dos meios eletrônicos, que de alguma forma incorpora características arcaicas e na qual as noções de hierarquia e indivíduo são cada vez mais questionadas. Neste novo ambiente, a Igreja enfrenta não só um processo de secularização muito forte, mas a emergência de novas formas de espiritualidade não-institucionais.

Assim, a Igreja foi forçada a modificar sua liturgia com o propósito de agregar novas formas midiáticas de comunicação com os fiéis. Daí os esforços do Concílio Vaticano II. McLuhan (2010), nota que, apesar da prioridade dada às mídias e à comunicação, a Igreja não tinha a mínima ideia das verdadeiras causas dessas alterações. O exemplo do fim da missa em latim é instrutivo. Para o teórico canadense com a introdução dos microfones nas paróquias o murmúrio particular do latim tornou-se insuportável nas missas, o que levou a Igreja a adotar línguas locais nas celebrações. A queda do latim, portanto, é consequência da introdução de um objeto técnico no ritual.

De acordo com McLuhan, a Igreja não podia lidar com a crise da ideia de indivíduo e hierarquia, a ponto de ele não vislumbrar um futuro para a instituição, considerada por ele anacrônica no contexto de aldeia global. Assim, enquanto o Papa continuasse em Roma para administrar uma estrutura de poder, a Igreja perderia cada vez mais sua legitimidade. Para McLuhan, a burocracia, por natureza, mantém-se por um longo tempo não importando o quão radicais sejam as mudanças, mesmo depois que o próprio aparato torna-se inútil (MCLUHAN, 2010, p. 83).

Enquanto católico, McLuhan lamentava o fato que a Igreja não era capaz de se adaptar eficazmente a esta nova realidade, optando sempre por medidas paliativas, como aquelas do Concilio Vaticano II. Segundo ele, os parâmetros dos novos meios poderiam, até mesmo, reforçar muitos preceitos caros ao cristianismo, 
como o alcance de uma condição pentecostal de compressibilidade universal e unidade a partir da metalinguagem informática (MCLUHAN, 1994, p. 80).

Evidentemente, o contexto tecnológico atual é bem distinto deste descrito pelo teórico. Se por um lado as inovações nos meios digitais reforçaram a crise da hierarquia e da individualidade, por outro lado a Igreja adotou nos últimos anos uma posição claramente mais incisiva face aos meios de comunicação, tanto no plano da ação estratégica como no plano reflexivo. Desde o pontificado de João Paulo II, a figura do Papa foi radicalmente transformada. O atual papa, Francisco I, é um personagem que viaja ao redor do mundo, e está sempre presente no espaço midiático, sobretudo, nas redes sociais.

Entretanto, o desejo de McLuhan de ver uma Igreja mais descentralizada ainda é um ideal distante e muitas das inconsistências por ele reportadas ainda são válidas. A maioria das preocupações da Igreja estão focados no conteúdo das mensagens e na estratégia de transmissão e não em entender ou absorver as mudanças que a forma rede impõe, independentemente do seu conteúdo. A tensão frente à hierarquia, tal qual indicada por McLuhan em relação ao surgimento da eletricidade é, no caso do digital, ainda mais radical. Com essa nova ecologia dos meios, as distinções de identidade entre o emissor e o receptor são abolidas. Assim, a vontade de descentralização torna-se cada vez mais forte.

A comunicação digital é caracterizada pelo processo de circulação e fluxo de informações sem centro e periferia que tende a substituir as hierarquias sociais e religiosas por formas de construção colaborativa de conteúdos e experiências (CASTELLS, 2007). A autoridade espiritual, que é a defensora de uma verdadeira visão do mundo, enfrenta esta multiplicação radical de vozes, inclusive no contexto do catolicismo: a profusão de websites ditos católicos fora do controle oficial exemplifica essa realidade.

As hierarquias religiosas, mesmo que elas busquem enfrentar os desafios desta nova condição de vida, como é o caso da Igreja Católica, confrontam-se 
cotidianamente com um cenário onde a sua legitimidade está concretamente enfraquecida. Quando a Igreja difunde uma mensagem e a defesa de uma única verdade através das arquiteturas digitais (sites, Facebook, YouTube, Twitter, etc.), essa mensagem entra em um labirinto sem fim de alternativas e visões sincréticas. Assim, esta nova atmosfera que começou com eletricidade e se radicalizou com o digital, antes de representar a época da crise do catolicismo, ela representa a saturação de um ideal de instituição.

\section{0 conflito entre diálogo e disseminação}

Outro mal-estar causado pela presença católica nas redes vem da diferença entre a doutrina da comunicação baseado na ideia de disseminação construída ao longo da tradição católica e a nova lógica digital, caracterizada por um modelo de comunicação dialógica. Disseminação e diálogo são as duas formas de comunicação que o filósofo americano John Durham Peters considera como as formas fundamentais da história da teoria da comunicação. Duas formas de comunicação que podem ser representados por dois personagens: Sócrates e Jesus. Se Sócrates de Platão é a figura central da concepção dialógica de comunicação, Jesus é a figura central da disseminação.

Podemos compreender esse ideal cristão de comunicação no interior do próprio texto bíblico. Assim, o que faz de Jesus o promotor da estratégia de disseminação é o uso de parábolas, especialmente as parábolas do Reino presentes nos Evangelhos. Considerada a parábola das parábolas, o episódio bíblico narrado nos Evangelhos de Mateus, Marcos e Lucas descrito como a parábola do semeador, mostra-nos com clareza a doutrina da comunicação cristã (PETERS, 2000). Nesse episódio, Jesus, enfrentando a oposição constante à sua mensagem, decidiu aproveitar a linguagem simbólica das parábolas para trazer a multidão aos mistérios do reino de Deus. O Semeador, que seria a princípio o próprio Jesus, lança os grãos em todos os lugares e em todos os tipos de solo. Muitas das sementes 
caíram à beira do caminho, nas pedras e espinhos e são perdidas, não dando frutos. No entanto, há grãos que caíram em boa terra e, portanto, produziram bons frutos.

Evidentemente, poderíamos relativizar esse ideal de disseminação mostrando como, mesmo na bíblia, existem elementos da comunicação dialógica. No mesmo capítulo da parábola do semeador, em Mateus, Jesus disse aos seus discípulos que uma verdadeira comunicação seria possível, isto é, a comunicação dialógica. No entanto, o povo, não estando preparado para receber diretamente a verdade, deveria ser iniciado a partir de outras estratégias, notadamente as parábolas. Nota-se que a presença da comunicação dialógica é absolutamente marginal, o cerne do ideal comunicativo é, naturalmente, a disseminação.

É interessante notar que esse ideal de disseminação encontrou na escrita o seu suporte por excelência. Afinal, é a materialidade deste meio que permitiu a estabilidade da mensagem cristã. A parábola do semeador, uma cena da tradição oral, foi imortalizada pela escrita e, assim, não está sujeita a alterações típicas da oralidade. Dessa forma, a mensagem pode alcançar um público universal, não limitado pelo poder da voz do emissor. A parábola do semeador pode ser lida, no limite, como uma ode à escritura que poderia estender essa estratégia de disseminação para um público mais vasto.

Assim, consideramos que a estratégia de disseminação acompanhou todas as mudanças paradigmáticas dos meios de comunicação. E a Igreja, por sua vez, aproveitou-se de cada um desses novos meios e as formas de comunicação doravante engendrados, como a imprensa e a mídia eletrônica, a partir dessa mesma estratégia. Em suma, cada nova tecnologia serviu para multiplicar exponencialmente o poder de disseminação no âmbito da Igreja.

Uma questão importante que surge a partir do ponto de vista da instituição e dos pesquisadores que estudam a presença católica nas redes é saber se a Internet permitiria uma disseminação mais ampla, tendo em conta sua configuração material e técnica particular. Para a igreja, a resposta é sim, como percebemos 
neste trecho da mensagem de Bento XVI para o dia mundial das comunicações sociais de 2013:

A capacidade de utilizar as novas linguagens requer-se não tanto para estar em sintonia com os tempos, como sobretudo para permitir que a riqueza infinita do Evangelho encontre formas de expressão que sejam capazes de alcançar a mente e o coração de todos. No ambiente digital, a palavra escrita aparece muitas vezes acompanhada por imagens e sons. Uma comunicação eficaz, como as parábolas de Jesus, necessita do envolvimento da imaginação e da sensibilidade afetiva daqueles que queremos convidar para um encontro com o mistério do amor de Deus (BENTO XVI, 2013).

Para a instituição, a principal função da Internet é seu poder de disseminação sem precedentes. Disseminação não só do conteúdo institucional, mas sobretudo das boas novas do Reino de Deus. A mensagem da Igreja atingiria espacialidades inimagináveis, “até aos confins do mundo” (Act 1, 8). É por isso que, para a Igreja, a internet é um dom de Deus, um recurso proposto por Deus para a disseminação das boas novas.

Trata-se de uma perspectiva providencialista dos meios de comunicação, tal como concebida por um dos teólogos mais influentes da comunicação do século XX, padre Émile Gabel, que descrevia cristo como um grande comunicador. Como bem analisa D. Douyère, o teólogo entende as novas tecnologias como meios para cumprir o plano de Deus, permitindo uma rede de comunicação universal aberta para Cristo (DOUYÈRE, 2001). Em outras palavras, o teólogo exalta o poder de disseminação sem precedentes dos novos meios, o que, evidentemente, é potencializado com as tecnologias digitais. Encarar esses meios como dons de Deus legitima o grande investimento institucional na comunicação social.

No entanto, interpretar as redes apenas pelo seu poder de disseminação significa analisá-las apenas a partir de uma única perspectiva. Existem pelo menos duas concepções possíveis das redes digitais: uma concepção que expressa a capacidade de difundir informações em larga escala e sem intermediários e outra que enfatiza a capacidade dialógica. A documentação oficial da igreja e as reflexões 
teológicas destacam mais claramente a primeira concepção. O aspecto dialógico é secundário e o diálogo proposto é, com raras exceções, aquele que tem por objetivo a apresentação da mensagem de Deus: "É preciso saber-se inserir no diálogo com os homens e mulheres de hoje, para compreender os seus anseios, dúvidas, esperanças, e oferecer-lhes o Evangelho, isto é, Jesus Cristo, Deus feito homem, que morreu e ressuscitou para nos libertar do pecado e da morte" (FRANCISCO, 2014).

Se o objetivo das tecnologias de comunicação é oferecer o Evangelho a um público cada vez maior, a essência dos novos meios é o seu poder de disseminação, fazendo com que a perspectiva comunicativa continue na chave da instrumentalidade. Acreditamos que a observação das redes a partir da perspectiva dialógica é mais fértil para a compreensão do novo meio em toda a sua potência. A natureza dialógica das redes não deve ser entendida apenas como a livre troca de opiniões e pontos de vista entre os cristãos, mas como o estabelecimento de novas relações entre os diferentes modos de existência, humanos e não-humanos.

Essas novas relações podem induzir o surgimento de novas formas de vivenciar a espiritualidade, que podem estar em oposição aos dogmas e ao paradigma de comunicação da igreja. A ideia de rede de diálogo engendra novas formas de religiosidades, próximas - muitas vezes - ao paganismo, precisamente por facilitar a conexão entre os seres humanos, arquiteturas e interfaces de informação e a natureza em um complexo ecossistema onde a disseminação e o controle da definição do religioso, fundamentais para a Igreja Católica como instituição, é muito comprometido.

Essa contradição entre a ideia de disseminação preconizada pelo cristianismo e, por conseguinte, pelo catolicismo enquanto instituição e a atual condição dialógica reticular provoca um desconforto no posicionamento da Igreja face às redes digitais. Afinal, assim como a mensagem cristã pode ser facilmente difundida nas redes, essa mesma mensagem pode, ao mesmo tempo, ser subvertida 
nessas mesmas redes a partir de diferentes pontos de vista e de concepções de mundo distintas articuladas e espalhadas por meio de uma dinâmica de colaboração na qual os próprios cristãos católicos são os maiores protagonistas, como é facilmente observável nas mensagens difundidas pelos chamados homossexuais católicos ou pelos católicos pró-aborto.

Além disso, a disponibilidade dos ritos on-line, como as famosas velas virtuais presentes em vários sites oficiais católicos, permite uma apropriação livre por parte dos usuários, o que, muitas vezes, se aproxima de práticas do paganismo. A difusão oficial de um rito, apesar de todas as limitações impostas pelo sistema desenvolvido pelo programador, torna-se um elemento de diálogo digital para os usuários que adotam essa prática como um elemento do misticismo tecnológico e que escapa a dimensão de mera utilidade tal como concebida pela instituição, tornando-se, portanto, algo fora do controle da Igreja

Decerto, essas práticas não podem ser definidas como uma concessão controlada pela instituição, que permitiria que o cristão agisse como um coprodutor da fé, afinal, como observamos aqui, o próprio controle da instituição na definição e exercício do religioso, fundamentais para a existência dela, é constantemente ameaçado por essas novas práticas. Uma vez disseminados, esses ritos entram em um complexo domínio imaginário e dialógico no qual a dimensão utilitária autorizada é absolutamente superada. O equilíbrio institucional da religião católica no contexto das redes digitais é sempre precário. Tomemos o exemplo do rito da vela virtual. Apesar das limitações impostas pelo sistema, como limite de caracteres, essas velas podem ser facilmente subvertidas: um simples símbolo de oração pode tornar-se um dispositivo mágico, de tal sorte que o papel de mediação da igreja é comprometido. 


\section{Mensagem para além do meio}

Na tradição teológica católica há vários elementos que nos permitem interpretar o papel dos meios de comunicação como instrumentos de transmissão de uma mensagem que é, por natureza, imutável. Assim, as estratégias de comunicação podem variar com o tempo e com as condições históricas, mas a ideia de verdade proferida nunca muda.

Uma das fontes dessa teoria da comunicação católica, ou mesmo de uma teologia da comunicação, são os escritos de Agostinho. Em seu projeto intelectual, encontramos as principais doutrinas filosóficas de uma abordagem da comunicação que sustenta a neutralidade dos meios. Notadamente na obra De doctrina Christiana, observamos o desenvolvimento de um método de compreensão das escrituras e de entendimento do que caracterizaria a boa formação cristã. No texto, Agostinho distingue duas formas de conhecimento: o conhecimento sobre as coisas e o conhecimento sobre signos. Sobre o conhecimento das coisas, os homens têm duas tendências, o desejo de desfrutar e o desejo de utilizar: "Fruir é aderir a alguma coisa por amor a ela própria. E usar é orientar o objeto de que se faz uso para obter o objeto ao qual se ama, caso tal objeto mereça ser amado"(AGOSTINHO, 2002, p. 44).

A fim de dar uma imagem ilustrativa ao seu entendimento sobre os desejos de fruir e usar, Agostinho faz uma comparação com uma viagem de retorno à terra natal. Nessa viagem, não podemos apreciar os meios de transporte, mas apenas usá-los para alcançar o nosso objetivo final, que é a chegada. Para Agostinho, se alguém desfruta desses meios por eles mesmos, ou chega tarde ou nem mesmo chega ao destino final. Eis a metáfora de uma jornada que representa a vida terrena como transitória e os objetos materiais e visíveis, em última instância o mundo inteiro, como meio para chegar ao que interessa: de civitate Dei, a cidade de Deus, isto é, a eternidade. 
Em suma, para Agostinho, o mundo é entendido como meio (medium) para chegar a Deus, pois é usando as coisas visíveis que os homens atingem o invisível. O filósofo sustenta que Deus criou os meios para que os homens possam usá-los para se aproximar das coisas que realmente devem ser amadas, isto é, o próprio Deus. Para ele, todas as coisas que não são Deus, são meios, no sentido mais amplo da palavra, isto é, são intermediários. Devido a esse estatuto dos meios, não se deve amá-los, mas apenas usá-los como algo transitório. Os sistemas de transporte, de comunicação, e o próprio mundo são meios. Amar essas instâncias intermediárias significa afastar-se do destino.

É dessa maneira que devemos nos encaminhar rumo a Deus, pois é somente a partir do visível que alcançamos o invisível. Isso significa que Deus, enquanto ser amórfico, aparece aos homens por meio das coisas visíveis, conforme nos mostra Agostinho em Cidade de Deus (Cf. Livro X, Cap. XIII). Nesse trecho de sua obra maior, o filósofo defende que dado a sua invisibilidade, Deus deve, para se tornar visível, aparecer de tal forma que os homens o reconheçam, isto é, de forma visível. Sendo essa forma outra coisa que Deus, mas, ao mesmo tempo, o próprio Deus.

A verdade de Deus, por uma deficiência humana, deve aparecer em carne mortal, porque os homens não podem reconhecer a sabedoria de Deus em si. Destarte, como está escrito no famoso versículo de João: “E o Verbo se fez carne, e habitou entre nós" (Jo 1,14). O que Agostinho nos chama a atenção a propósito desse versículo é que essa habitação, ou mediação pela carne mortal, não transforma a natureza da mensagem: “...a palavra de Deus, sem mudar de natureza, fez-se carne para habitar entre nós" (AGOSTINHO, 2002, p. 52). O que vemos em jogo, aqui, é a ideia da carne como meio, isto é, como uma ferramenta neutra na qual nada foi alterado na descida em forma sensível do invisível. Assim, a natureza da mensagem divina permanece a mesma, independente do novo suporte. A carne é apenas um expediente de transmissão sem valor ontológico, pois o conteúdo é o mesmo, independentemente da materialidade: 


\begin{abstract}
Nem o pensamento e nem a Palavra perdem-se em seu descenso para a forma sensível. A natureza permanece constante em um novo suporte. Incorporação é na melhor das hipóteses um expediente de exibição, sem importância ontológica. Este é o programa da comunicação como o encontro de duas ideias interiores, imperturbável por suas materialidades. O conteúdo permanece idêntico em todas as suas incorporações (PETERS, 2000, p. 70).
\end{abstract}

Assim, não se pode tomar o senso a partir das coisas intermediarias, isto é, o meio não é a mensagem. O senso profundo da mensagem está para além dos meios, dos signos: "Na realidade, é para alma uma escravidão de causar pena, o tomar os signos pelas coisas e se sentir impotente de erguer o olhar da inteligência acima da criação temporal, a fim de enchê-lo da luz eterna" (AGOSTINHO, 2002, p. $161 ; 162)$.

O que se delineia nesse trecho da obra De doctrina christiana é uma teoria dos meios, entendidos num sentido amplo como meios de comunicação, transporte, signos linguísticos ou mesmo, no limite, todo o mundo material. Esses meios são canais neutros que não têm o poder de transformar a mensagem, pois eles devem ser utilizados e não amados em si. Mesmo essa utilização deve ser moderada, isto é, para fins legítimos, ao contrário não é utilização, mas abuso: "O uso ilícito cabe, com maior propriedade, o nome de excesso ou abuso"(AGOSTINHO, 2002, p. 44).

Para Agostinho, a comunicação acontece graças e apesar do meio. Paradoxo da comunicação, que é sempre indireta. No caso da comunicação indireta entre homem e Deus, o único intermediário legitimo é Jesus Cristo; uma comunicação que é formatada para os sentidos humanos. O Deus cristão comunica-se a partir de uma manifestação, a encarnação de Cristo, o verbo de Deus. Essa encarnação é antes de tudo um ato comunicativo; em consequência, a comunicação divina para com os homens é sempre indireta (DOUYÈRE, 2013).

Entretanto, conforme desenvolve Agostinho em Cidade de Deus (Livro 16, Capítulo 6), nem toda comunicação é indireta. Deus tem uma maneira de se 
comunicar perfeita, por exemplo com os anjos, uma comunicação que dispensa a mediação, o meio. Mas, ressalta Agostinho, se os homens estiverem especialmente abertos a Deus, é possível ultrapassar a mediação e apreender Deus nele mesmo. Mesmo a aparência de Deus é um problema comunicativo, afinal, Deus não possui aparência em forma física. Assim, quando ele se torna visível, o que se observa é uma mediação, e não o próprio Deus.

Podemos concluir que o sonho ou utopia da teologia da comunicação é a dispensa do meio para o alcance da verdade em si, isto é, um processo comunicativo sem intermediários. É exatamente essa a utopia simbolizada na comunicação entre anjos, uma comunicação entre interioridades, sem matéria, sem mediação, a única verdadeira comunicação. Agostinho deixa em aberto que a comunicação sem mediação pode ser uma aspiração humana; ao mesmo tempo em que problematiza e destaca o perigo da incomunicabilidade.

Ao analisarmos o discurso e, sobretudo, a prática comunicacional da Igreja, pode-se perceber a atualidade do pensamento agostiniano. A neutralidade da matéria e a imutabilidade da mensagem divina por ele estabelecidas acompanham, de certa forma, as estratégias comunicacionais da Igreja enquanto instituição. A imprensa, o rádio, a televisão e as mídias digitais são instrumentos de divulgação da mensagem divina, são o aspecto material e visível por meio do qual o invisível se manifesta.

A partir dessa perspectiva, é possível argumentar que os meios - inclusive as tecnologias de comunicação - são fundamentais para a manifestação de Deus, pois sem essas tecnologias esse contato seria impossibilitado. O que justifica todo o investimento que a Igreja vem empreendendo nas novas mídias. Assim, o digital, como a tecnologia de nosso tempo, não seria um mero coadjuvante no processo, mas teria um papel central. Entretanto, coerente com essa doutrina, essas novas tecnologias, tais como as anteriores, são concebidas enquanto instrumentos aos quais se deve usar e não amar em si: "a revolução nos meios de comunicação e de 
informação são um grande e apaixonante desafio que requer energias frescas e uma imaginação nova para transmitir aos outros a beleza de Deus”(FRANCISCO, 2014). O próprio Papa deixa claro que essa utilização deve ser direcionada para os fins dignos, caso contrário é abuso e não utilização. No limite, existe a defesa de um estilo católico de estar presente nas redes, com toda a dimensão que essa atitude implica, e é dessa prerrogativa que decorre toda a crítica ao mau uso das redes.

É preciso mencionar, entretanto, que há tentativas por parte dos pensadores da Igreja de escapar da retórica da boa utilização das redes, como declara Spadaro:

Se os cristãos refletem sobre a Rede, não é somente para aprenderem a "usá-la" bem, mas por que foram chamados a ajudar a humanidade a compreender o significado profundo da própria Rede no projeto de Deus: não como um instrumento a ser usado, mas como um ambiente a ser habitado (SPADARO, 2012, p. 11).

Todo esforço de Spadaro está em contribuir com um pensamento comunicacional e teológico para além da concepção meramente instrumental. Por isso a ideia de que as redes engendram um novo habitar contemporâneo no qual a Igreja não só deve estar presente como cooperar para sua compressão. É preciso reconhecer que a Igreja se afasta significativamente de uma postura iconoclasta e tecnofóbica, não só recomendando o uso, como encorajando a presença nesse ambiente. Todavia, mesmo não sendo um instrumento específico, mas um ambiente, este não deve ser usufruído em si. O cuidado eclesiástico em não sucumbir ao elogio da sacralização do objeto técnico é patente.

A esse respeito, recordemos que Jacques Ellul, teólogo e tecnólogo protestante, denunciava que a transferência da sacralidade à tecnologia forjava uma mística infecunda que conduziria o homem à alienação e à escravidão (ELLUL, 2003, p. 316). É dentro dessa perspectiva que a presença alentada pela Igreja tem como objetivo exclusivo aproximar as pessoas do reino de Deus, coerentemente com a doutrina agostiniana. Por isso as redes digitais, enquanto meios, não mudam ou transformam a natureza da mensagem, mas somente 
constituem os caminhos contemporâneos rumo a Deus. No limite, as redes digitais não devem ser amadas e muito menos sacralizadas, mas, antes, apenas utilizadas.

\section{Conclusão}

Disseminação e diálogo, uso e fruição, hierarquia e horizontalidade. Eis três contraposições que provocam paradoxos na presença da Igreja nas redes. A igreja busca atenuá-las: timidamente valoriza e incentiva o diálogo; busca outras formas de participação que não aquela vertical; e insiste, finalmente, na afirmação que o grande desafio da Igreja não é saber como bem usar as tecnologias, mas saber como acomodar-se a essa nova realidade na qual as redes não seriam meros instrumentos mais ambientes que todos nós habitamos.

Contudo, essas contraposições continuam presentes e surgem independentemente do que se publica nos documentos oficiais e do conteúdo da comunicação presente nos sites ou redes sociais da instituição. Elas são, antes, o resultado de um choque entre as novas configurações que o medium digital impõe e a estrutura própria da Igreja. Desse choque, diversas outras transformações ocorreram no seio da instituição. Foi assim com o surgimento da tipografia e da eletricidade, inovações tecnológicas anteriores que provocaram mudanças tão profundas na paisagem midiática quanto a inovação digital. Os primeiros sinais desse processo na atualidade já são visíveis, o atual papado nos fornece exemplos contundentes nessa direção. Difícil prever se as contradições apontadas neste artigo são superáveis a partir de um esforço deliberado da Igreja em adaptar-se ao novo espírito do tempo, afinal, trata-se de uma das instituições mais tradicionais do Ocidente, o que em si significa um grande empecilho para qualquer processo de transformação profunda.

Entretanto, a temporalidade das dinâmicas sociais é outra. Elas seguem na velocidade das redes. Assim, mesmo que o advento das redes digitais tenha 
acelerado o processo de crise das religiões-instituições, que marcou toda a modernidade, isso não significa que vivemos em um período de dessacralização ou desencanto, ao contrário, vivemos num momento de retorno da mística e da espiritualidade, justamente no bojo do secularismo (MAFFESOLI, 2009). Em suma, vivemos em um período marcadamente politeísta e de espiritualidade difusa (AGUIAR, 2014).

Não se trata, pois, da declaração da crise do catolicismo, enquanto crença e prática. O que vemos nas novas ritualidades reticulares é um processo de ressignificação constante. Assim, se é ainda nebuloso conceber uma nova Igreja, decerto não restam dúvidas que um novo catolicismo emerge, relativamente autônomo da instituição, vivenciado na vida cotidiana e que preza pelas dinâmicas dialógicas, pela fruição dos objetos tecnológicos como bens em si e pela horizontalidade, características típicas do meio digital.

\section{REFERÊNCIAS}

AGOSTINHO. A doutrina cristã. Manual de exegese e formação cristã. São Paulo: Paulus, 2002.

AGOSTINHO. La Cité de Dieu. In: Oeuvres II. [Paris]: Gallimard, 2000.

AGUIAR, C. E. S. A Sacralidade Digital: as religiões e religiosidades na época das redes. São Paulo: FAPESP : Annablume, 2014.

BENTO XVI, Papa. Redes Sociais: portais de verdade e de fé; novos espaços de evangelização. 2013. Disponível em: < goo.gl/VxwDXB >. Acesso em: 22 mar. 2016.

CASTELLS, M. A sociedade em rede. São Paulo: Paz e Terra, 2007.

DOUYÈRE, D. De l'usage chrétien des médias à une théologie de la communication : le père Émile Gabel. Le Temps des médias. Communiquer le sacré dossier, v. 2, n. 17, 2001.

DOUYÈRE, D. L'Incarnation comme communication, ou l'auto-communication de Dieu en régime chrétien. Questions de communication, n. 23, p. 31-56, 31 ago. 2013.

ELLUL, J. Les Nouveaux Possédés. Paris: Mille et une nuits, 2003. 
FRANCISCO, Papa. Comunicação ao serviço de uma autêntica cultura do

encontro. Mensagem para o $48^{\circ}$ dia mundial das comunicações sociais. Vaticano, 2014.

Disponível em: <http://goo.gl/UMH61g>. Acesso em: 5 jun. 2014

MAFFESOLI, M. Le réenchantement du monde: une éthique pour notre temps. Paris: Perrin, 2009.

MCLUHAN, M. Understanding media: the extensions of man. 1st MIT Press ed ed. Cambridge, Mass: MIT Press, 1994.

MCLUHAN, M. The medium and the light: reflections on religion. Eugene, Or.: Wipf \& Stock, 2010.

MEYROWITZ, J. No sense of place: the impact of electronic media on social behavior. New York: Oxford University Press, 1985.

ONG, W. The presence of the word: some prolegomena for cultural and religious history. Binghamton, N.Y.: Global Publications, 2000.

PETERS, J. D. Speaking into the air: a history of the idea of communication. Chicago: University of Chicago Press, 2000.

SPADARO, A. Cyberteologia: pensare il cristianesimo al tempo della rete. Milano: V\&P, 2012. 